RESEARCH ARTICLE

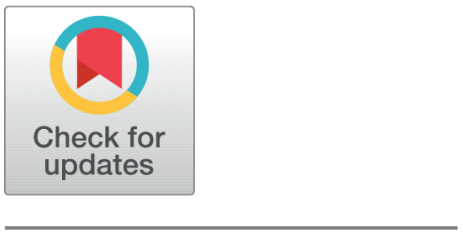

OPEN ACCESS

Received: 19.10 .2020

Accepted: 15.01 .2021

Published: 02.02.2021

Citation: Intra P,

Wanusbodeepaisarn $\mathrm{P}$,

Siri-achawawath T (2021)

Performance evaluation of corona discharger for unipolar chargingof submicron aerosol particles in the size range of 20-300 $\mathrm{nm}$. Indian Journal of Science and Technology 14(4): 335-350. https://doi.org/ 10.17485/IJST/v14i4.1878

* Corresponding author.

panich_intra@yahoo.com

Funding: None

Competing Interests: None

Copyright: ( $) 2021$ Intra et al. This is an open access article distributed under the terms of the Creative Commons Attribution License, which permits unrestricted use, distribution, and reproduction in any medium, provided the original author and source are credited.

Published By Indian Society for Education and Environment (iSee)

ISSN

Print: 0974-6846

Electronic: 0974-5645

\section{Performance evaluation of corona discharger for unipolar chargingof submicron aerosol particles in the size range of $20-300 \mathrm{~nm}$}

\author{
Panich Intra ${ }^{1 *}$, Paisarn Wanusbodeepaisarn ${ }^{2}$, Thanesvorn Siri-achawawath \\ 1 Research Unit of Applied Electric Field in Engineering (RUEE), College of Integrated Science \\ and Technology, Rajamangala University of Technology Lanna, Chiang Mai, 50220, Thailand \\ 2 Pico Innovation Co., Ltd., 336 M. 4, Yang Noeng, Saraphi, Chiang Mai, 50140, Thailand \\ 3 Innovative Instrument Co., Ltd., 7/139 Suntinakorn 11 Alley, Bang Kaeo, Bang Phli, Samut \\ Prakan, 10540, Thailand
}

\section{Abstract}

Objectives: In this study, a unipolar corona discharger was developed and experimentally evaluated for its intrinsic and extrinsic charging efficiencies, and electrostatic and diffusion losses of submicron aerosol particles in the size range of $20-300 \mathrm{~nm}$ at different corona and ion trap voltages. Method: The applied voltage of the discharger ranged between 2.4 and $3.2 \mathrm{kV}$, corresponding to a discharge current of $0.19 \mathrm{nA}-2.0 \mu \mathrm{A}$, and an ion number concentration of $1.88 \times 10^{11}-1.97 \times 10^{15}$ ions $/ \mathrm{m}^{3}$. Findings: Increasing the corona voltage could lead to a higher discharge current and ion concentration inside the discharger. In the proposed discharger, intrinsic charging efficiencies of aerosol particles between $76.9 \%$ and $93.0 \%$ were obtained for particle sizes ranging between 20 and $100 \mathrm{~nm}$ for the given corona and ion trap voltages. The extrinsic charging efficiency decreased as the ion trap voltage increased at a given corona voltage. Novelty: The optimal extrinsic charging efficiency of the discharger was observed to be approximately $20.8-58.6 \%$ for particle sizes ranging from 20 to $300 \mathrm{~nm}$ at a corona voltage and ion trap voltage of approximately $2.8 \mathrm{kV}$ and $200 \mathrm{~V}$, respectively. In this discharger, the highest electrostatic losses (approximately 73.5\%, 83.7\%, and 54.0\%) were observed corresponding to corona voltages of $2.8,3.0$, and $3.2 \mathrm{kV}$, respectively at a particle diameter of $20 \mathrm{~nm}$ and an ion trap voltage of $300 \mathrm{~V}$. Finally, the highest diffusion loss (approximately 18.9\%) was observed at a particle diameter of $20 \mathrm{~nm}$.

Keywords: Corona discharge; particle charging; aerosol discharger; particle loss

\section{Introduction}

Nanoparticles are defined as particulate substances of nano-scale dimensions (typically less than $100 \mathrm{~nm}$ ). In atmospheric science, particles less than $100 \mathrm{~nm}$ are called ultrafine 
particles and most atmospheric nanoparticles are typically smaller than $50 \mathrm{~nm}$. On roadsides with heavy traffic, it has been shown that the particle count distribution peaks at 100-200 $\mathrm{nm}(0.1-0.2 \mu \mathrm{m})$. The diesel-exhaust particles are usually black carbonaceous soot with submicron particles of diameters typically ranging from 30 to $500 \mathrm{~nm}(0.03-0.5 \mu \mathrm{m})$. They are the major components of fine particles or PM2.5 ${ }^{(1)}$. A regulation for PM2.5 concentrations was promulgated by the U.S. Environmental Protection Agency ${ }^{(2)}$. With regard to the PM2.5 standards, the Federal Reference Method is adopted, which is based on a gravimetric analysis of particles, collected on filters over a period of $24 \mathrm{~h}^{(2)}$. As the epidemiological studies consider the relationship between mortality and morbidity, and ambient particle exposures use particulate data, the gravimetric analysis is selected. However, a 24-h average measurement may not sufficiently demonstrate human exposure. Therefore, a real-time airborne PM2.5 monitor is desirable. A number of methods have been incorporated in the instruments to achieve real-time airborne PM2.5 monitoring, including beta ray absorption, light scattering, quartz microbalances, and electrical aerosols.

A new electrical aerosol method has been developed to measure the number concentration of submicron aerosol particles in real-time for over the past decade ${ }^{(3)}$. The electrical aerosol technique generally comprises particle charging and particle charge detection. The charged particles in an air flow are eliminated on the high-efficiency particulate-free air (HEPA) filter inside the detector chamber, resulting in a particle charge current, whose magnitude is proportional to the mean charge per particle, number concentration of particles, and mass flow rate. Recent developments in electrical aerosol devices were reviewed by Intra and Tippayawong ${ }^{(4)}$. In the electrical method, particle charging is one of the most important components in measuring the particle number concentration. The purpose of particle charging is to impose a known charge distribution on the aerosol particles. Because the number concentration of particles is normally determined by measuring the electrical charge of aerosol particles, the prediction of particle number concentration requires a knowledge of the charging efficiency for every particle size. The particle charging efficiency, defined as the fraction of charged particles among all the particles present at the discharger outlet, is the most important performance parameter of a particle discharger. Typically, an ideal particle discharger requires a high particle charging efficiency with a high ion number concentration, no gas-to-particle conversion (formation of unwanted byproducts including particles), low agglomeration between charged particles, low particle losses, no contamination, and applicability to submicron aerosol particles ${ }^{(5)}$.

The unipolar corona discharger is widely used as a particle discharger ${ }^{(6)}$ owing to its simple electrode configuration and design, lower cost of fabrication and maintenance, and ability to provide stable and high ion concentrations ${ }^{(5)}$. The corona discharge is a relatively low-power electrical discharge that occurs at or near atmospheric pressure. A corona is invariably generated by a strong electric field associated with small diameter wires, needles, or sharp edges on an electrode. If the electric field strength is sufficiently high, the gas can undergo a spark discharge or electrical breakdown. In this corona discharge region, electrons will have sufficient energy to knock an electron from gas molecules, thus generating positive ions and free electrons. In the conventional charging process, aerosol particles flow through a cloud of unipolar ions in the discharge region. Ions diffuse toward the particles and collide with them. Upon collision, there are, in principle, two possible ways by which the particle can acquire a charge: (a) either the ions physically attach themselves to the surface of the particle, or (b) there is an exchange of electrons between the particle and the impinging ion. The amount of charge per particle depends on the charging time, particle diameter and shape, electrical field strength, etc. A variety of corona dischargers have been developed to improve the charging efficiency of submicron aerosol particles ${ }^{(7-18)}$, and a number of electrical aerosol devices have employed unipolar corona dischargers ${ }^{(19-25)}$ as important upstream components to provide a known net charge distribution to the particle system. However, the loss of charged particles owing to electrostatic and diffusion effects are often severe, and need to be addressed in the development and modification of unipolar corona dischargers. Several of the existing unipolar corona dischargers reported previously require a clean air flow to generate an ion-rich gas jet ${ }^{(7-9,13)}$. Thus, it is difficult to efficiently charge submicron aerosol particles without relying on clean air or preventing clean air from diluting the particles. In our previous work ${ }^{(26)}$, a simple corona-needle discharger that does not require clean air flow was designed and its electrostatic characteristics were experimentally evaluated. It was capable of charging particles at high concentrations and high penetration of ions. However, the intrinsic and extrinsic charging efficiencies in this discharger were poor in submicron aerosol particles smaller than $300 \mathrm{~nm}$ owing to high particle losses caused by (i) the strong electric field in the charging region of the discharger, and (ii) the diffusion and electrostatic effects during the particle transport in the discharger. Therefore, a well-designed unipolar corona discharger should yield high intrinsic and extrinsic charging efficiencies and low diffusion and electrostatic losses that can be accurately determined for the given operating conditions.

In this study, a novel and simple design of a unipolar corona discharger for charging submicron aerosol particles in the size range of 20-300 $\mathrm{nm}$ was developed and experimentally evaluated. The corona discharge characterization and particle charging performance of the discharger, including the current-to-voltage characteristics, intrinsic and extrinsic charging efficiencies of the particles, electrostatic loss, and diffusion loss were experimentally studied and discussed at different corona and ion trap voltages, and particle diameters. 


\section{Description of Unipolar Corona Discharger}

This study aims to develop a simple, compact, and low-cost corona discharger for unipolar aerosol charging with a robust operation that does not use additional ion-driving voltage, dilution, or clean air flows, and at the same time is easy to construct. The discharger should be capable of operating at low mass flow rates and low corona currents and voltages to reduce the energy consumption, while maintaining a high charging efficiency for submicron aerosol particles. Thus, the particle discharger of the electrical aerosol devices should be better suited for general applications of airborne particulate monitoring. Figure 1 illustrates a schematic diagram of the unipolar corona discharger for submicron aerosol particle charging in the size range of 20-300 nm developed in this work. The developed discharger was divided into two zones, namely a charging zone and an ion trap zone. The charging zone comprises a sharp corona-needle electrode, T-pipe electrode, and polytetrafluoroethylene (PTFE) insulator. The needle electrode was made of a stainless-steel rod, $2 \mathrm{~mm}$ in diameter, ending in a sharp tip. The needle electrode was polished using high precision taper point grinding and polishing machines to an extremely fine surface finish to avoid undesirable electric field effects on particle motion and loss owing to a non-uniform electric field, resulting from small surface scratches and imperfections. The needle cone angle was approximately $10^{\circ}$. The T-pipe electrode was made of a stainless-steel tube with an inner diameter of approximately $6 \mathrm{~mm}$. The PTFE insulator was an electrical isolator between the needle electrode and Tpipe electrode. The PTFE insulator served to hold the needle electrode to be coaxial with the T-pipe electrode. The distance between the needle electrode and T-pipe electrode apex was $6 \mathrm{~mm}$. The length of the charging zone of the discharger was approximately $6 \mathrm{~mm}$. The needle electrode could be screwed into the PTFE insulator to connect it to a positive DC high-voltage source (Model 602C-100P, Spellman High Voltage Electronics Corporation, Blvd Hauppauge, NY, USA), typically in the range of $2.8-3.2 \mathrm{kV}$, while the T-pipe electrode was electrically grounded so as to produce the required corona discharge field. The discharge generated positive ions that moved rapidly in the strong discharge field toward the wall of the T-pipe electrode. The positive polarity was set for the corona voltage in the developed discharger. This is because the production rate of ozone in the negative corona was one order of magnitude higher than in the positive corona ${ }^{(27)}$, and the negative corona revealed fluctuations and dependence on surface conditions ${ }^{(28)}$. The discharge current I can be calculated using the Townsend equation ${ }^{(29)}$ :

$$
I=a V\left(V-V_{c}\right)
$$

Where $\mathrm{V}$ is the applied voltage; $\mathrm{V}_{c}$ is the corona onset voltage; and a is the dimensional constant depending on the interelectrode distance, needle electrode radius, charge carrier mobility in the drift region, and other geometrical factors. Therefore, the ion concentration $\mathrm{N}_{i}\left(\right.$ ions $/ \mathrm{m}^{3}$ ) as a function of the discharge current of the discharger can be estimated by ${ }^{(26)}$

$$
N_{i}=\frac{I_{c h}}{e Z_{i} E_{c h} A_{c h}}
$$

where $I_{c h}$ is the discharge current of the discharger; e is the elementary charge $\left(1.61 \mathrm{X}^{-19} \mathrm{C}\right) ; \mathrm{Z}_{i}$ is the electrical mobility of

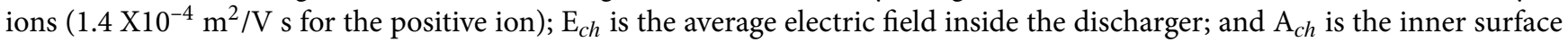
area of the charging zone of the discharger, where the discharge current is collected, and can be calculated as

$$
A_{c h}=1.5 \pi r L
$$

Where $r$ is the radius of the T-pipe electrode and $\mathrm{L}$ is the length of the charging zone of the discharger. The inner surface area of the charging zone of the discharger was estimated to be $8.5 \times 10^{-5} \mathrm{~m}^{2}$. If the space charge effect is neglected, the electric field inside the corona discharger as a function of the distance between the corona-needle electrode tip and the T-pipe electrode is assumed to be given by the Mason equation ${ }^{(30)}$ as

$$
E(\xi)=\frac{2 V}{\left(r+2 \xi-\xi^{2} / d\right) \ln (1+4 d / r)}
$$

where $\mathrm{V}$ is the applied voltage; $\mathrm{r}$ is the radius of the needle electrode tip; $\xi$ is the distance from the needle electrode tip along the $\mathrm{z}$-axis; and $\mathrm{d}$ is the distance between the needle electrode tip and T-pipe electrode. In the developed discharger, the average electric field in the charging zone ranged between $8.89 \times 10^{5}$ and $1.02 \times 10^{6} \mathrm{~V} / \mathrm{m}$ for applied voltages between 2.8 and $3.2 \mathrm{kV}$. At the needle electrode tip, $\xi=0$; therefore, the expression for the electric field in Equation (4) becomes ${ }^{(31)}$

$$
E_{\max }=\frac{2 V}{r \ln (1+4 d / r)}
$$

Equation (5) is typically used in the literature for estimating the electric field at a needle electrode tip ${ }^{(30,31)}$. The electric field at the needle electrode tip in the charging zone of the developed discharger was approximately $4.01 \mathrm{X} 10^{6}-4.58 \mathrm{X} 10^{6} \mathrm{~V} / \mathrm{m}$ for 
applied voltages of 2.8-3.2 kV. In this discharger, the particle flow was directed across the corona discharge field and charged by ion-to-particle collisions via diffusion charging and field charging mechanisms. The discharger performance was dependent on the stable ion concentration $\left(\mathrm{N}_{i}\right)$; furthermore, the mean charging time of the particles to the ions $(\mathrm{t})$ in the charging zone of the discharger is given by

$$
t=\frac{\pi r^{2} L}{Q_{p}}
$$

Where $\mathrm{Q}_{p}$ is the particle mass flow rate. In this work, the charging time of the discharger was approximately $17 \mathrm{~ms}$ when the particle mass flow rate was approximately $0.6 \mathrm{~L} / \mathrm{min}$ at a Reynolds number of approximately 2,120 . For this reason, a welldesigned discharger should yield a stable $N_{i} t$ product that can be accurately determined for the given operating conditions.

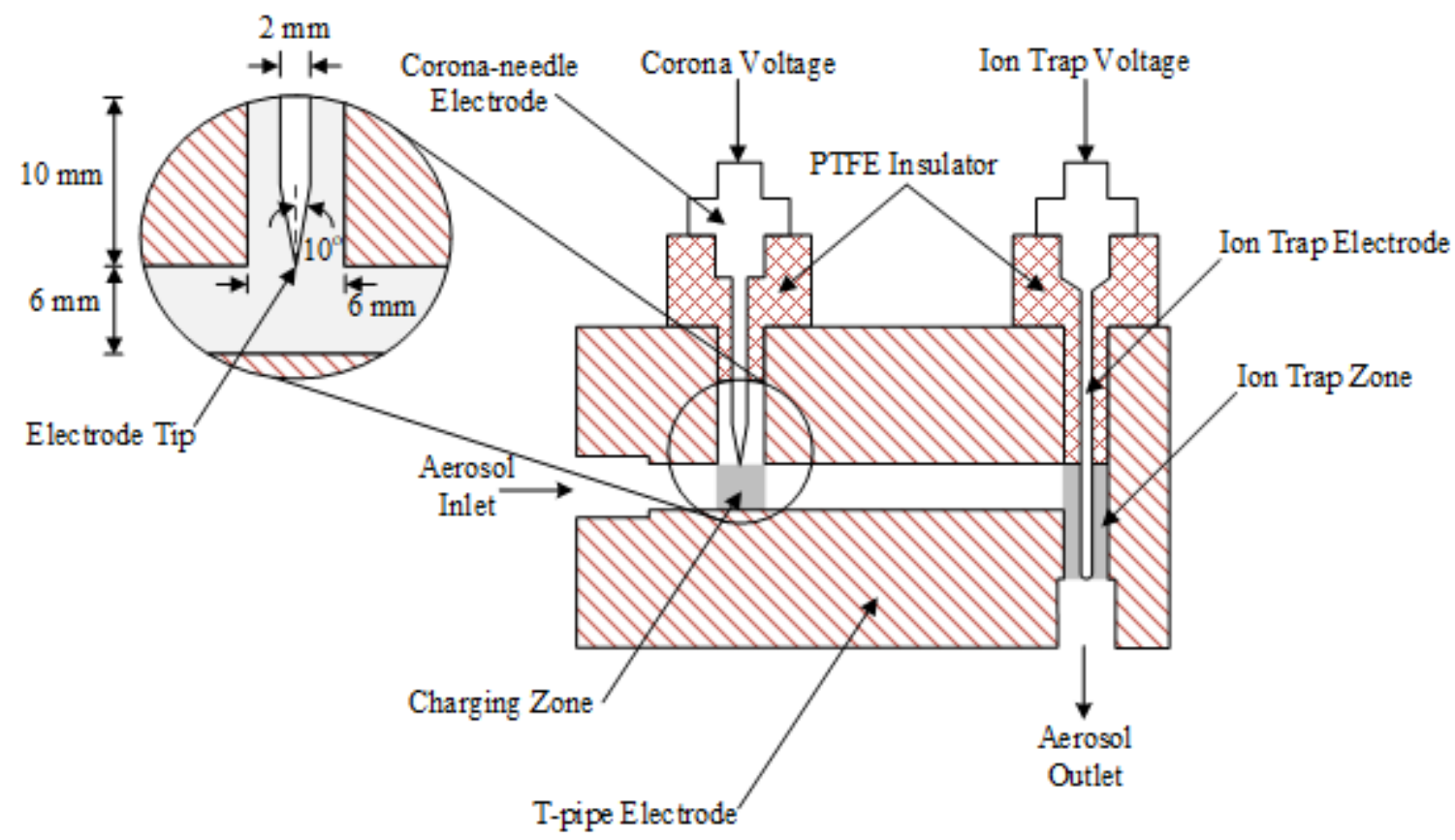

Fig 1. Schematic diagram of the developed corona discharger

As depicted in Figure 1, the ion trap zone prevents the excess free positive ions from mixing with the charged particles, and in turn, prevents contamination of the signal current to be measured by free ions that can potentially reach the detector. The ion trap zone consisted of an ion trap electrode placed along the axis of a T-pipe electrode. The T-pipe electrode, a stainless-steel tube, was approximately 6 and $15 \mathrm{~mm}$ in diameter and length, respectively. The trap electrode, a stainless-steel electrode, had a diameter and length of 2.5 and $15 \mathrm{~mm}$, respectively. To generate an electric field inside the ion trap zone for the removal of free positive ions, a positive DC voltage power source (Model 602C-100P, Spellman High Voltage Electronics Corporation, Blvd Hauppauge, NY, USA) was applied to the trap electrode, typically in the range of 200-300 V, while the T-pipe electrode was electrically grounded. When the free positive ions with a high electrical mobility entered the ion trap zone, the electrostatic force drove them toward the T-pipe electrode and the ions were deposited on the wall of the T-pipe electrode; however, most of the charged particles were unaffected. The ion removal efficiency $\eta_{\text {tr ap }}$ of the ion trap zone of the discharger can be estimated by the Deutsch-Anderson equation as ${ }^{(32,33)}$

$$
\eta_{\text {trap }}=1-\exp \left(-\frac{Z_{i} E_{\text {rap }} A_{\text {trap }}}{Q_{p}}\right)
$$

where $E_{\text {trap }}$ is the average electric field inside the ion trap zone of the discharger and $A_{\text {tr ap }}$ is the inner surface area of the ion trap zone of the discharger. 
Table 1 summarizes a comparison between the existing dischargers and the propo $_{s}$ ed discharger in terms of the geometrical configuration of the electrodes, particle mass flow rate, applied voltage range, particle flow behavior, Nit product, and extrinsic charging efficiency. The differences between the proposed and existing dischargers are as follows: (i) The proposed discharger is based on a simple design; it is compact, has a low cost, and comes as a portable unit to reduce the production and operational costs (its dimensions are 44X90X25 mm; furthermore, it costs less than 150 USD). It has been shown that it is not necessary to use these relatively complicated designs to obtain reasonably high charging efficiencies. In fact, a simple grounded electrode with a coaxial needle electrode is adequate to achieve efficiencies practically identical to those attainable with the considerably more complex dischargers. (ii) A T-pipe electrode configuration with a short charging zone was used to reduce the diffusion losses of the particles and eliminate the charged particle loss by electrostatic collection inside the discharger. It could be operated at a low aerosol flow rate to reduce the cost and energy consumption of the flow control system, which could be a mass flow meter with a controller or a vacuum pump that is suitable for long-term measurement in the field. (iii) An ion trap was used to remove the excess free positive ions mixing with the charged particles to prevent the contamination of the measured signal current by the free ions potentially reaching the detector. (iv) The proposed discharger does not use any additional ion-driving voltage and dilution or clean air flows. (vi) Finally, the applied voltage was set to maintain a low level to reduce the energy consumption while maintaining a high charging efficiency for submicron aerosol particles.

Table 1. Comparison between existing dischargers and this discharger

\begin{tabular}{|c|c|c|c|c|c|c|c|c|}
\hline & Whitby $^{(6)}$ & $\begin{array}{l}\text { Medved et } \\
\text { al. }^{(7)}\end{array}$ & $\begin{array}{l}\text { Marquard et } \\
\text { al. }^{(8)}\end{array}$ & $\begin{array}{l}\text { Hernandez- } \\
\text { Sierra et } \\
\text { al. }^{(9)}\end{array}$ & $\begin{array}{l}\text { Alonso et } \\
\text { al. }{ }^{(10)}\end{array}$ & $\begin{array}{l}\text { Park et } \\
\text { al. }{ }^{(12)}\end{array}$ & $\begin{array}{l}\text { Intra and } \\
\text { Tippaya- } \\
\text { wong }{ }^{(13)}\end{array}$ & This work \\
\hline $\begin{array}{l}\text { Needle } \\
\text { electrode } \\
\text { diameter }\end{array}$ & $\mathrm{n} / \mathrm{a}$ & $\mathrm{n} / \mathrm{a}$ & $\mathrm{n} / \mathrm{a}$ & $3 \mathrm{~mm}$ & $\mathrm{n} / \mathrm{a}$ & $0.25 \mathrm{~mm}$ & $3.0 \mathrm{~mm}$ & $2 \mathrm{~mm}$ \\
\hline $\begin{array}{l}\text { Orifice diam- } \\
\text { eter }\end{array}$ & $1.5 \mathrm{~mm}$ & $\mathrm{n} / \mathrm{a}$ & $15 \mathrm{~mm}$ & $4 \mathrm{~mm}$ & $3.5 \mathrm{~mm}$ & $\mathrm{n} / \mathrm{a}$ & $3.5 \mathrm{~mm}$ & - \\
\hline $\begin{array}{l}\text { Electrodes } \\
\text { distance }\end{array}$ & $6.4 \mathrm{~mm}$ & $\mathrm{n} / \mathrm{a}$ & $10 \mathrm{~mm}$ & $3.5 \mathrm{~mm}$ & $3 \mathrm{~mm}$ & $\mathrm{n} / \mathrm{a}$ & $3.5 \mathrm{~mm}$ & $6 \mathrm{~mm}$ \\
\hline $\begin{array}{l}\text { Charging } \\
\text { zone length }\end{array}$ & $\mathrm{n} / \mathrm{a}$ & $\mathrm{n} / \mathrm{a}$ & $\mathrm{n} / \mathrm{a}$ & $20 \mathrm{~mm}$ & $15 \mathrm{~mm}$ & $\mathrm{n} / \mathrm{a}$ & $20 \mathrm{~mm}$ & $6 \mathrm{~mm}$ \\
\hline $\begin{array}{l}\text { Particle flow } \\
\text { rate }\end{array}$ & $70 \mathrm{~L} / \mathrm{min}$ & $1.2 \mathrm{~L} / \mathrm{min}$ & $\begin{array}{l}11-20 \\
\mathrm{~L} / \mathrm{min}\end{array}$ & $2-8 \mathrm{~L} / \mathrm{min}$ & $\begin{array}{l}2-10 \\
\mathrm{~L} / \mathrm{min}\end{array}$ & $5 \mathrm{~L} / \mathrm{min}$ & $\begin{array}{l}1-5 \\
\mathrm{~L} / \mathrm{min}\end{array}$ & $\begin{array}{l}0.6-5 \\
\mathrm{~L} / \mathrm{min}\end{array}$ \\
\hline $\begin{array}{l}\text { Corona } \\
\text { voltage range }\end{array}$ & $1-9 \mathrm{kV}$ & $\mathrm{n} / \mathrm{a}$ & $\mathrm{n} / \mathrm{a}$ & $2.5-4 \mathrm{kV}$ & $\begin{array}{l}3.1-3.7 \\
\mathrm{kV}\end{array}$ & $3.5-5 \mathrm{kV}$ & $\begin{array}{l}2.2-3.6 \\
\mathrm{kV}\end{array}$ & $2.8-3.2 \mathrm{kV}$ \\
\hline $\begin{array}{l}\text { Particle direc- } \\
\text { tion }\end{array}$ & Perpendicular & Perpendicular & Perpendicular & Perpendicular & Circular & Perpendicular & Circular & Perpendicular \\
\hline Clean air flow & No & Yes & Yes & NO & No & Yes & No & No \\
\hline Ion trap & No & No & No & No & No & Yes & No & Yes \\
\hline $\mathrm{N}_{i} \mathrm{t}$ product & $\mathrm{n} / \mathrm{a}$ & $\mathrm{n} / \mathrm{a}$ & $\mathrm{n} / \mathrm{a}$ & $\begin{array}{l}2-8 \times 10^{7} \\
\mathrm{~s} / \mathrm{cm}^{3}\end{array}$ & $\begin{array}{l}1-4 \times 10^{7} \\
\mathrm{~s} / \mathrm{cm}^{3}\end{array}$ & $\begin{array}{l}1-7 \times 10^{7} \\
\mathrm{~s} / \mathrm{cm}^{3}\end{array}$ & $\begin{array}{l}2 \quad-8 \times 10^{7} \\
\mathrm{~s} / \mathrm{cm}^{3}\end{array}$ & $\begin{array}{l}1.7 \times 10^{7} \\
\mathrm{~s} / \mathrm{cm}^{3}\end{array}$ \\
\hline $\begin{array}{l}\text { Extrinsic } \\
\text { charging } \\
\text { efficiency }\end{array}$ & $\mathrm{n} / \mathrm{a}$ & $40 \%$ at $10 \mathrm{~nm}$ & $\mathrm{n} / \mathrm{a}$ & $\begin{array}{l}30 \% \text { at } 10 \\
\mathrm{~nm}\end{array}$ & $\begin{array}{l}5 \% \text { at } 13.6 \\
\mathrm{~nm}\end{array}$ & $\mathrm{n} / \mathrm{a}$ & $\mathrm{n} / \mathrm{a}$ & $\begin{array}{l}20.8 \% \text { at } 20 \\
\mathrm{~nm}\end{array}$ \\
\hline
\end{tabular}

$\mathrm{n} / \mathrm{a}$ : information not available

\section{Experimental Setup}

\subsection{Current-to-voltage characteristics}

Figure 2 depicts the experimental setup for evaluating the current-to-voltage characteristics of the developed discharger. It consists of a developed discharger, an adjustable DC high-voltage power source, and an electrometer. A positive voltage between 2.0 and $3.2 \mathrm{kV}$ was applied to the needle electrode of the discharger with an adjustable commercial DC high-voltage power source. In this experiment, no voltage was applied to the trap electrode; therefore, a positive voltage of $0 \mathrm{~V}$ was maintained at the trap electrode using a second adjustable commercial DC voltage power source. The discharge currents in the discharge 
zone of the discharger were directly measured using an electrometer (Model 6517A, Keithley Instruments, Inc., Cleveland, OH, USA) via the T-pipe electrode, which was electrically grounded.

DC High Voltage Power Source

(Spellman's Bertan model 602C-100P)
DC High Voltage Power Source (Spellman's Bertan model 602C-100P)

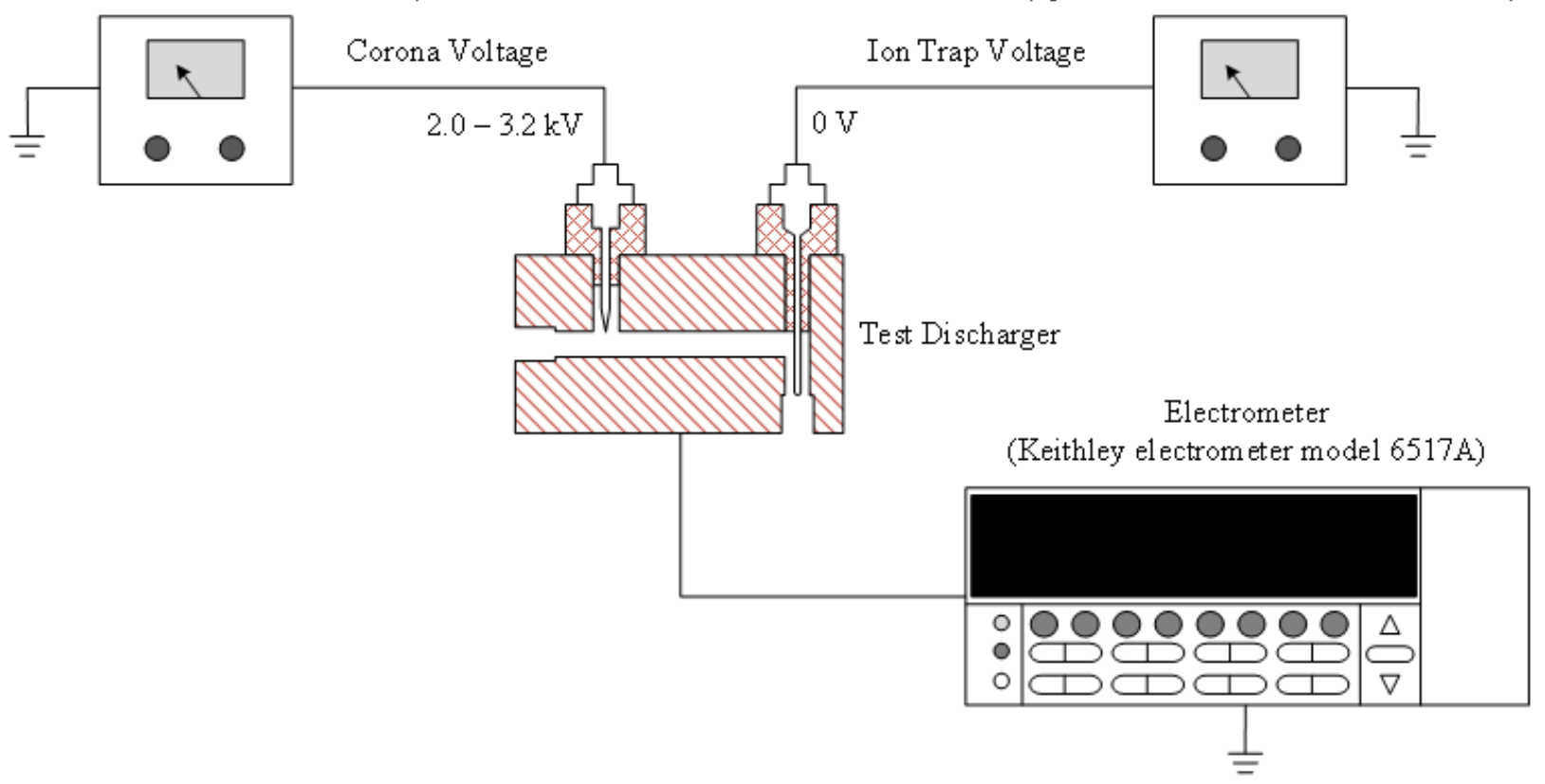

Fig 2. Experimental setup for investigating the current-to-voltage characteristics of the developed discharger.

\subsection{Charging efficiency and particle loss determination}

Figure 3 depicts the experimental setup for evaluating the particle charging efficiency and particle losses in the developed discharger. Four indices were used for evaluating the particle charging performance of the developed discharger, which included the intrinsic charging efficiency $\left(\eta_{\text {in }}\right)$, extrinsic charging efficiency $\left(\eta_{e x}\right)$, electrostatic loss $L_{e l}$, and diffusion loss $L_{d}$. The setup consisted of a developed discharger, an adjustable DC high-voltage power source, an aerosol atomizer, a filtered air supply, an aerosol neutralizer, a concentration adjustment valve, a HEPA filter, a diffusion dryer, an electrostatic collector (ESC), an electrostatic classifier, and an ultrafine condensation particle counter (UCPC). In this study, sodium chloride ( $\mathrm{NaCl}$ ) polydisperse particles were produced by atomizing a $\mathrm{NaCl}$ solution (w/w $0.1 \%$ in water) with an aerosol atomizer (Model 3076, TSI Inc., St. Paul, MN, USA) and a filtered air supply (Model 3074B, TSI Inc., St. Paul, MN, USA). The polydisperse particles originating from the aerosol atomizer were still wet and hence, were dried to a relative humidity of less than $30 \%$ in a diffusion dryer (Model 3062, TSI Inc., St. Paul, MN, USA). It is well-known that the generated polydisperse particles have a certain level of electric charge ${ }^{(32)}$. Therefore, some loss of particles owing to the electrostatic charge in the system may be encountered, unless the particles are neutralized. Charged particles tend to deposit on the tube walls and other surfaces. A soft X-ray aerosol neutralizer (Model 3088, TSI Inc., St. Paul, MN, USA) was used to neutralize the particles and bring them to the Boltzmann charge equilibrium. In this system, the particle number concentration could be changed by adjusting the concentration adjustment valves and a HEPA capsule filter (Model 1602051, TSI Inc., St. Paul, MN, USA). The mean diameter, concentration, and geometric standard deviation of the generated particles were $59.8 \mathrm{~nm}, 4.54{ }^{\prime} 10^{5}$ particles $/ \mathrm{cm}^{3}$, and 2.0 , respectively, as depicted in Figure 4 . The $\mathrm{NaCl}$ polydisperse particles were then classified according to their electrical mobility using a soft X-ray aerosol neutralizer and an electrostatic classifier (Model 3082, TSI Inc., St. Paul, MN, USA), with a longdifferential mobility analyzer (DMA; model 3081, TSI Inc., St. Paul, MN, USA), with a clean air flow of $3.0 \mathrm{~L} / \mathrm{min}$, which allowed a mobility diameter of 10-600 $\mathrm{nm}$. The particles exiting the DMA at a given voltage were nearly singly charged monodisperse particles. The fraction of multiply charged large particles exiting the DMA was reduced to approximately $10 \%$ or less for all the particles in the size range of $20-300 \mathrm{~nm}$ by having the particle size distribution of the test particle centered around a mode diameter of approximately $30 \mathrm{~nm}$. The singly charged monodisperse particles were then passed through the second soft X-ray 
aerosol neutralizer and the first ESC, to which a positive voltage of approximately $3.0 \mathrm{kV}$ was applied by a DC high-voltage power source to entirely remove the charged particles. The uncharged monodisperse particles were obtained downstream from the first ESC. Only the uncharged particles were introduced into the discharger. After the charged particle flow exited the discharger, it passed through the second ESC. The charged aerosol flow was further made to enter a UCPC (Model 3788, TSI Inc., St. Paul, MN, USA) to measure the particle number concentration downstream of the developed discharger.

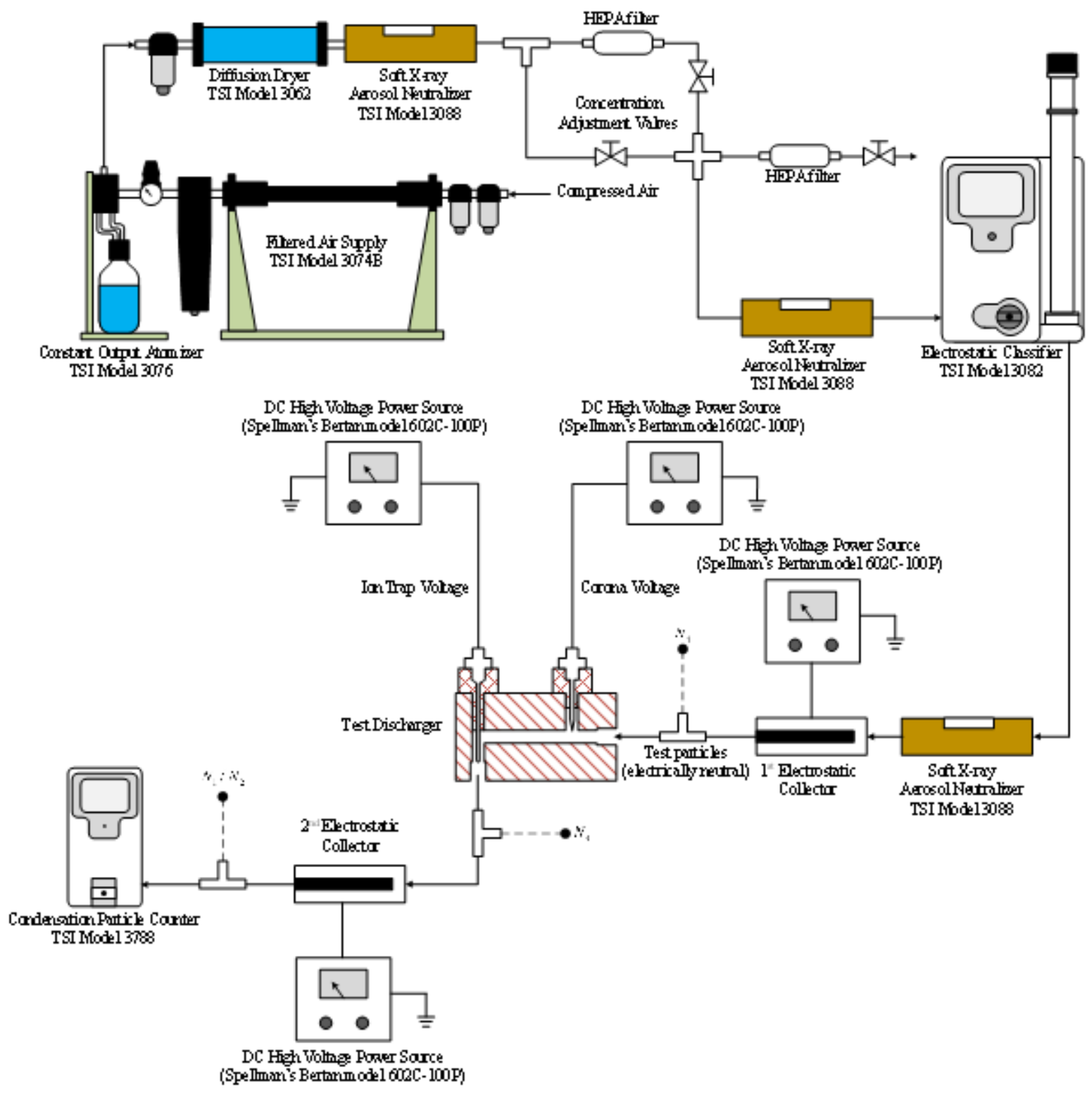

Fig 3. Schematic of the experimental setup for the measurement of particle loss, intrinsic and extrinsic charging efficiency of the developed discharger 


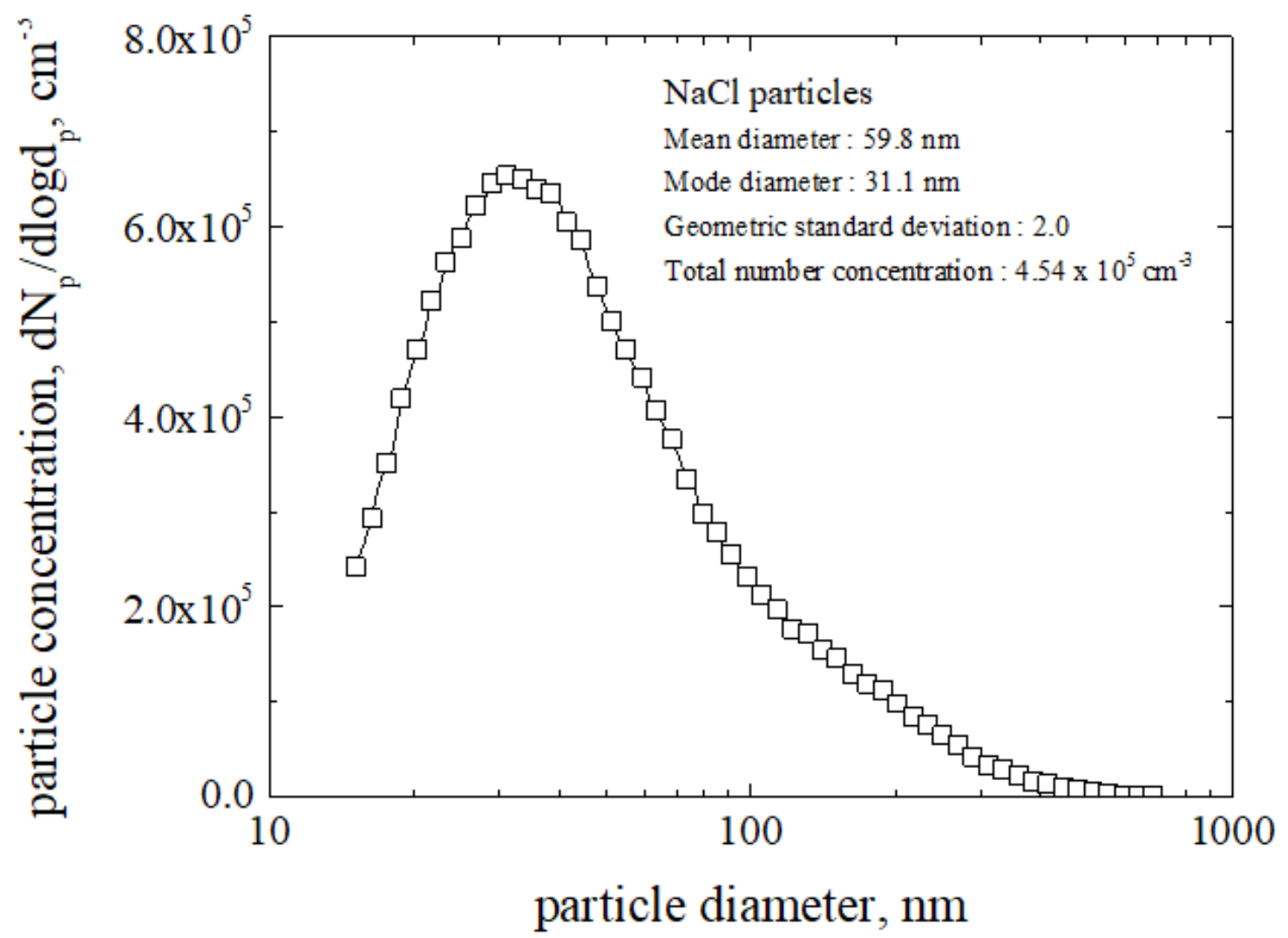

Fig 4. Nanoparticle concentration and size distribution of sodium chloride particles generated from an atomizer

In this study, both the charging efficiencies and losses of the discharger were measured at a particle mass flow rate of approximately $0.6 \mathrm{~L} / \mathrm{min}$. The intrinsic charging efficiency was calculated using ${ }^{(34)}$

$$
\eta_{\text {in }}=1-\frac{N_{1} / T}{N_{2}}
$$

Where $N_{1}$ is the number concentration of neutral particles downstream of the second ESC when the discharger and second ESC voltages were on; $N_{2}$ is the number concentration of total particles downstream of the second ESC when the discharger and the second ESC voltages were off; and $T$ is the transmission efficiency of the neutral particles passing through the second ESC. The extrinsic charging efficiency, which is a parameter of interest in a practical application, is defined as the fraction of particles exiting the discharger, carrying at least a unit of charge, and can be calculated by ${ }^{(34)}$

$$
\eta_{e x}=\frac{N_{3}-N_{1} / T}{N_{4}}
$$

where $N_{3}$ is the number concentration of charged particles downstream of the discharger, when the discharger voltage is on, and $N_{4}$ is the number concentration of neutral particles upstream of the discharger.

In this study, the electrostatic loss of particles $L_{e l}$ and diffusion loss $L_{d}$ inside the discharger were calculated using the following equations ${ }^{(11)}$ :

$$
\begin{gathered}
L_{e l}=\frac{N_{2}-N_{3}}{N_{4}} \\
L_{d}=1-\frac{N_{2}}{N_{4}}
\end{gathered}
$$




\section{Results and Discussion}

Figure 5 depicts the variations in the discharge current and ion concentration with the corona voltage of the developed discharger. The corona onset voltage of the developed discharger was approximately $2.4 \mathrm{kV}$. When the corona voltage increased from 2.4 to $3.2 \mathrm{kV}$, the discharge current increased from $0.19 \mathrm{nA}$ to $2.0 \mu \mathrm{A}$, while the ion concentration increased from $1.32 \mathrm{X} 10^{11}$ to $1.03 \mathrm{X} 10^{15} \mathrm{ions} / \mathrm{m}^{3}$, respectively. As a result, there was an ionization of the gas molecules and ignition of a corona discharge ${ }^{(29)}$. As shown in Equation (2), the ion number concentration inside the charging zone of the developed discharger could be controlled by the discharge current or the corona voltage. That is, an increase in the corona voltage could lead to a higher discharge current; therefore, more ions were generated from the surface of the needle electrode. This could possibly result in an increase in the intrinsic charging efficiency of the discharger. The electrical breakdown phenomenon occurred for applied voltages larger than $3.2 \mathrm{kV}$. Above this value, the discharge current was found to exhibit a fluctuation in an uncontrollable manner and no measurement could be made. Alonso et al. ${ }^{(11)}$ also reported that corona voltages larger than $3.6 \mathrm{kV}$ promoted the formation of new particles. These particles probably came from the corona-emitting electrode by erosion or sputtering ${ }^{(35,36)}$, or from gaseous contaminants present in the system ${ }^{(37)}$. For the latter, the following mechanism was proposed ${ }^{(38)}$ : (a) contaminant molecules are ionized in the corona discharge field; (b) these ions form cores, around which water molecules are bonded; (c) the contaminant-water elementary units grow into molecular clusters and finally, through coagulation, into nanometer-sized particles. The presence of water was thought to constitute a decisive factor in the particle generation process. It was shown that particle generation from organic vapors in air by corona discharge did not occur in the absence of water ${ }^{(39)}$. It can be stated that a clean corona discharger operating under an appropriate range of voltages did not produce new additional particles, as the aerosol did not contain impurities or certain chemicals (e.g., aromatic compounds with water). Therefore, a corona discharger can be used with confidence in most of the general research studies with aerosols of known composition; however, it is probably not a good option to use the same, for example, for measuring the size distribution of particles present in exhausts having contaminants that may undergo gas-to-particle conversion processes in the corona discharge. Thus, it was shown that the developed discharger could operate stably at applied voltages ranging from 2.8 to $3.2 \mathrm{kV}$.

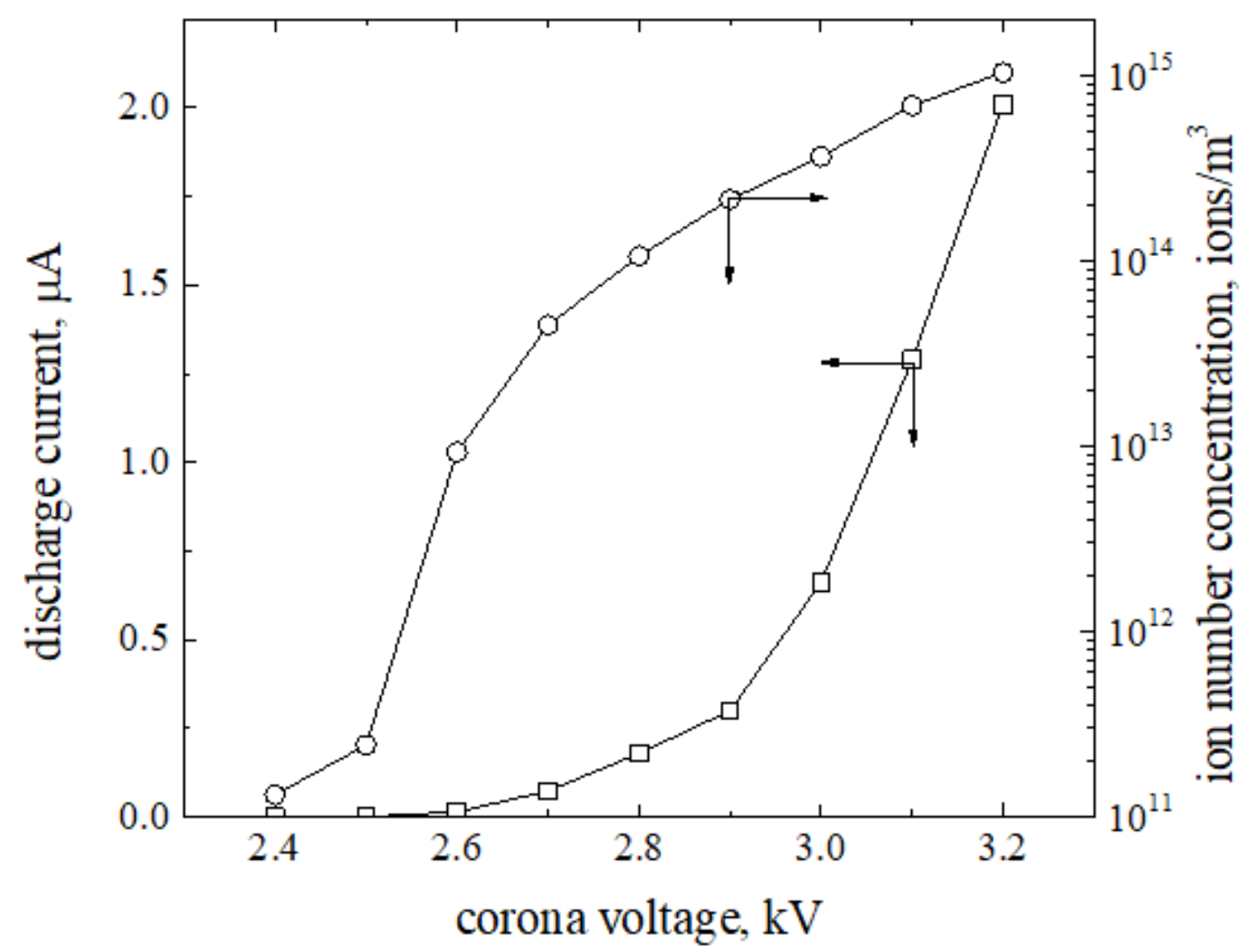

Fig 5. Variations in discharge current and ion number concentration with corona voltage of the developed discharger 
Furthermore, in this work, the intrinsic charging efficiency was evaluated at different corona voltages. Figure 6 depicts the intrinsic charging efficiency of the discharger as a function of the particle diameter in the range of 20-300 $\mathrm{nm}$ at various corona voltages. The test mass flow rate of the aerosol particles was fixed at approximately $0.6 \mathrm{~L} / \mathrm{min}$. The results indicate that the intrinsic charging efficiencies increased with an increase in the corona voltages at a given particle size. This result is explained by an increase in the probability of collisions of particles with ions owing to an increase in their concentration with the discharge current corresponding to the corona voltage ${ }^{(15)}$. At a given ion trap voltage, the intrinsic charging efficiencies increased from $74.09 \%$ to $94.40 \%, 78.53 \%$ to $94.60 \%$, and $79.90 \%$ to $95.08 \%$ with particle sizes in the range of approximately $20-50$ nm; likewise, they decreased from $93.12 \%$ to $77.96 \%, 93.36 \%$ to $76.91 \%$, and $93.95 \%$ to $78.86 \%$ with particle sizes in the range of approximately 150-300 nm for applied voltages of $2.8,3.0$, and $3.2 \mathrm{kV}$, respectively. The intrinsic charging efficiency also reached a constant value of $93 \%$ for particles in the size range of $50-100 \mathrm{~nm}$ at a given corona voltage. The intrinsic charging efficiency of a unipolar discharger is primarily affected by the ion number concentration $\left(N_{i}\right)$ and the particle residence time $(\mathrm{t})$ in the charging zone. The ion number concentration in the charging zone was controlled by varying the discharge current alone. At the particle mass flow rate of $0.6 \mathrm{~L} / \mathrm{min}$, the $N_{i} t$ values were approximately $1.79 \times 10^{12}$ and $1.76 \times 10^{13}$ ions $/ \mathrm{m}^{3} \mathrm{~s}$ at applied voltages of 2.8 and 3.2 $\mathrm{kV}$, respectively. However, the intrinsic charging efficiency can only present a part of the discharger performance. It is important to optimize the discharger performance and determine the optimal operating conditions of the discharger.

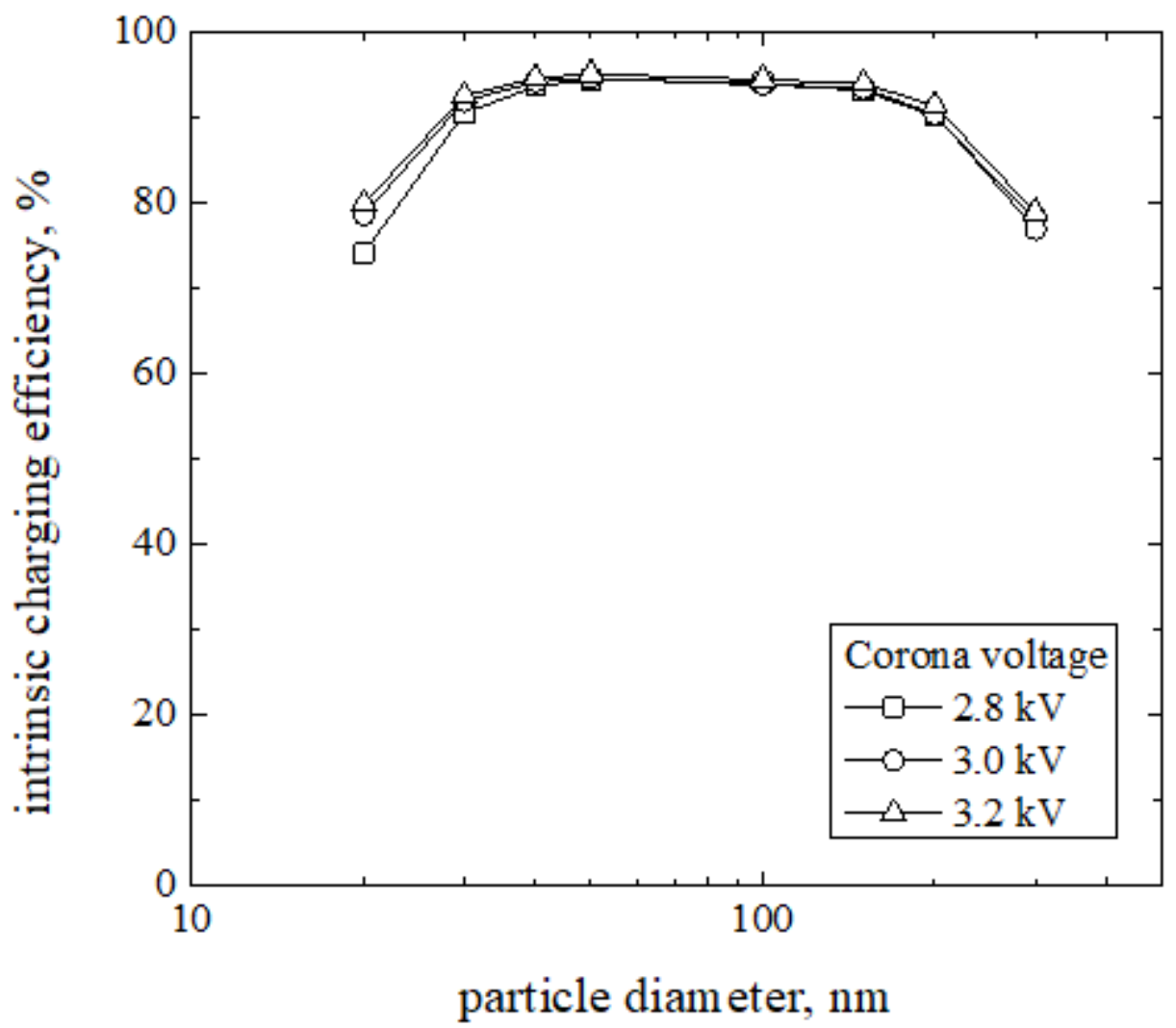

Fig 6. Intrinsic charging efficiency of the discharger as a function of particle diameter.

Figure 7 depicts the extrinsic charging efficiency of the discharger as a function of particle diameter in the range of 20$300 \mathrm{~nm}$ at various corona voltages and ion trap voltages. The particle mass flow rate was fixed at $0.6 \mathrm{~L} / \mathrm{min}$. The extrinsic charging efficiency takes into account the charged particle loss inside the discharger in comparison with the intrinsic charging efficiency. The results indicate that the extrinsic charging efficiency increased, as the particle size increased. In addition, a higher extrinsic charging efficiency could be obtained with a sufficiently high corona voltage at an appropriate ion trap and particle mass flow rate. At a given corona voltage, the extrinsic charging efficiency decreased as the ion trap voltage increased. The best extrinsic charging efficiencies of the discharger of approximately $20.80-58.62 \%$ for particle diameters ranging from 20 to $300 \mathrm{~nm}$ were observed at a corona voltage and ion trap voltage of approximately 2.8 and $200 \mathrm{~V}$, respectively. 


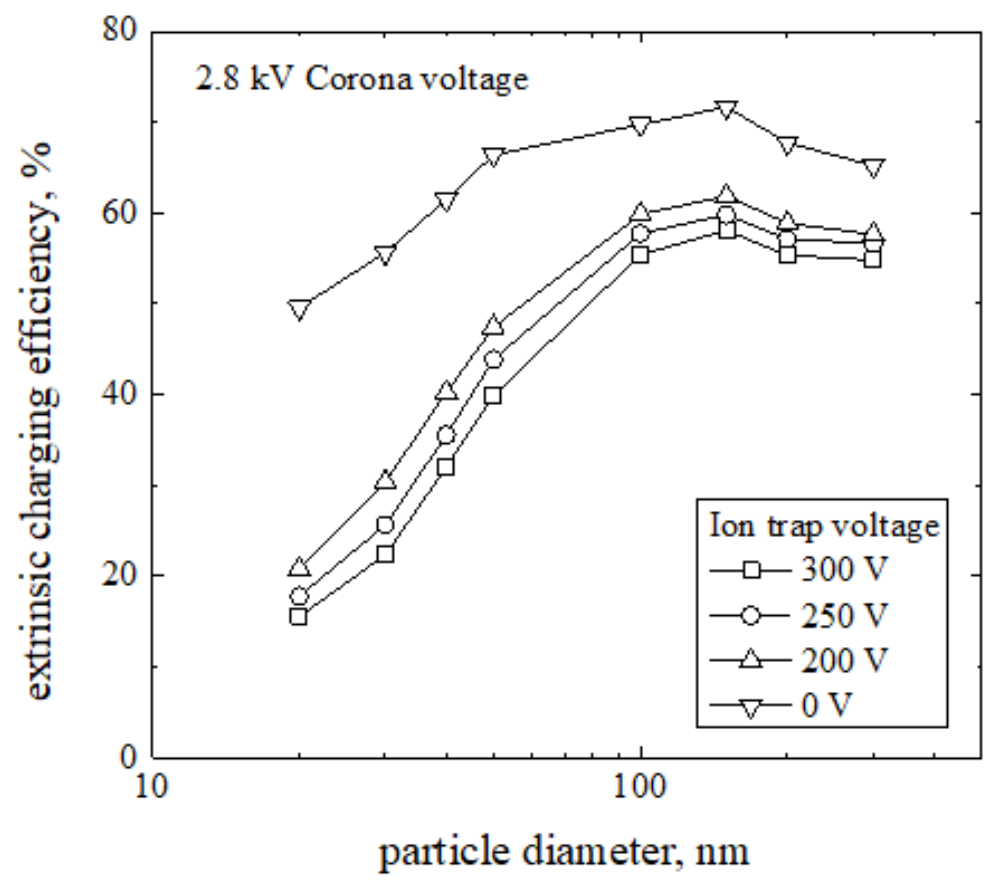

(a) $2.8 \mathrm{kV}$

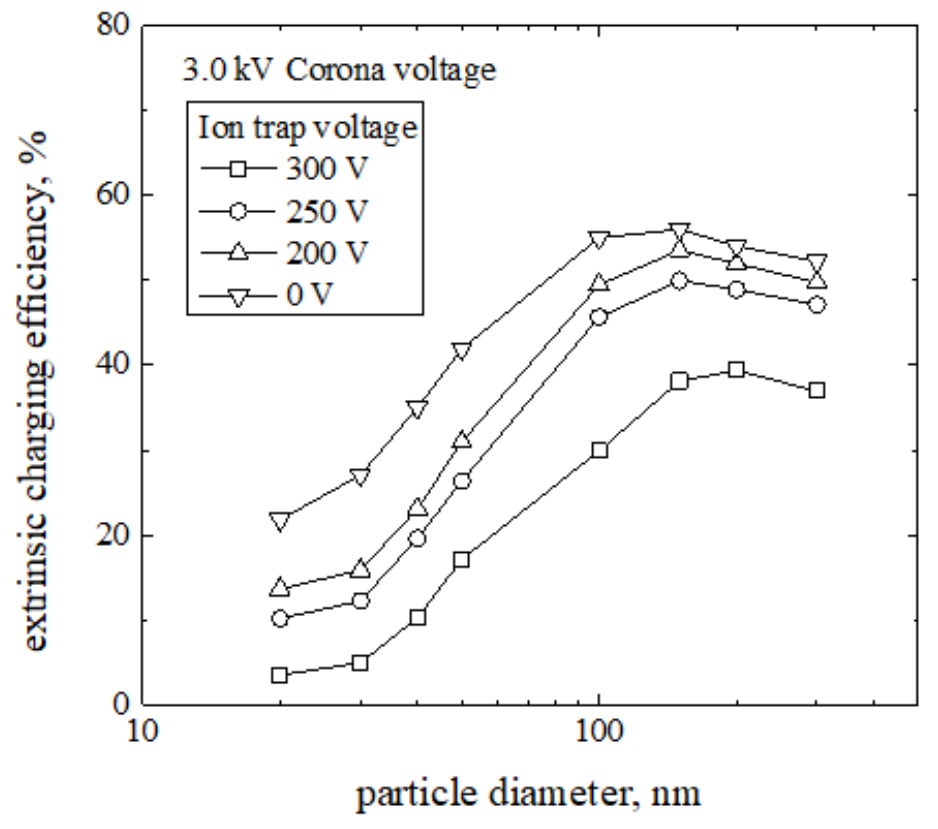

(b) $3.0 \mathrm{kV}$ 


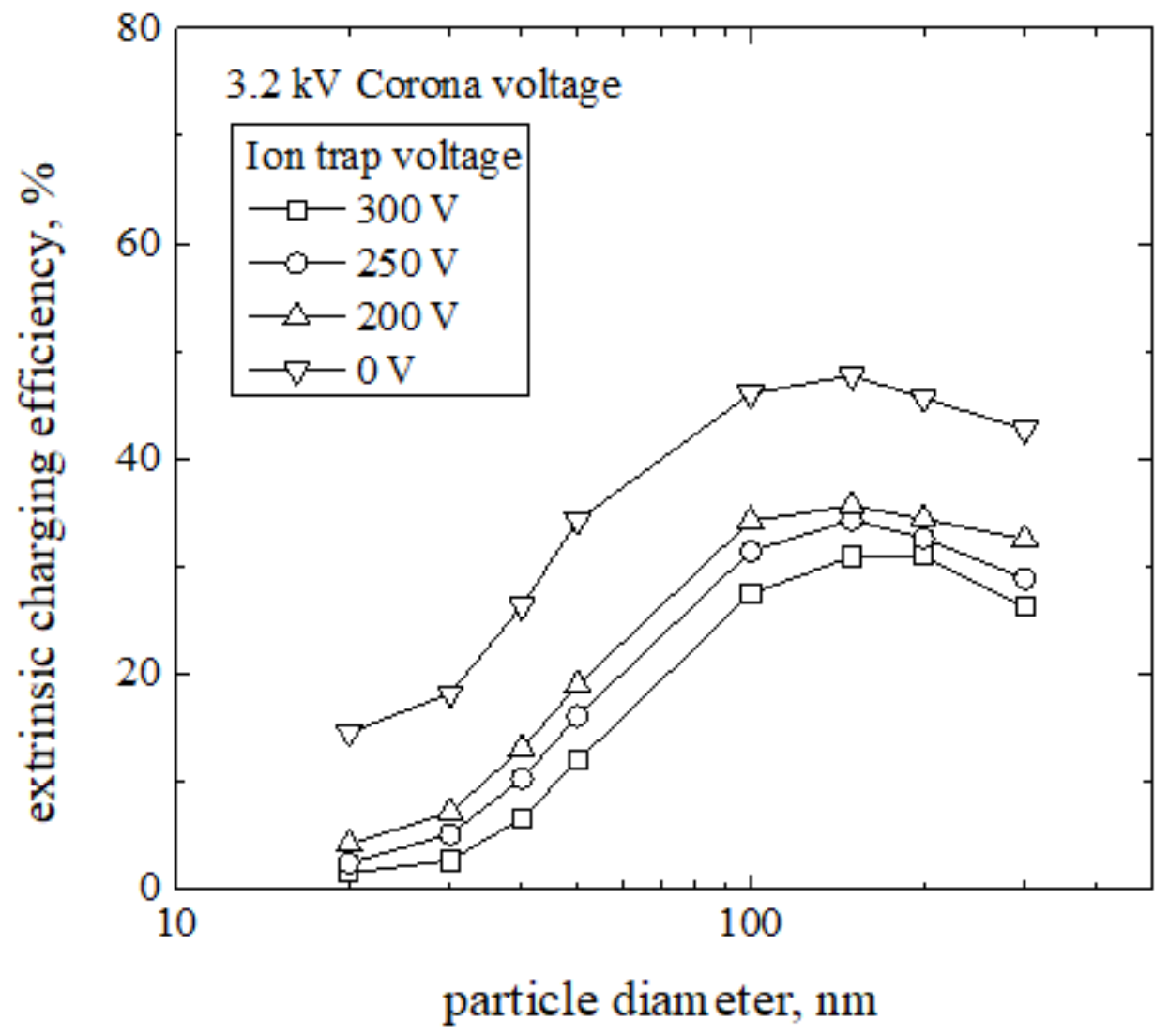

(c) $3.2 \mathrm{kV}$

Fig 7. Extrinsic charging efficiency of the discharger as a function of particle diameter.

As depicted in Figure 6, when the corona voltages were increased to raise the intrinsic charging efficiencies, it was important to allow the charged particles to pass through the discharger. The fraction of particles lost inside the discharger also needed to be reduced. Figure 8 reveals the electrostatic and diffusion losses of particles inside the discharger as a function of the particle diameter in the size range of $20-300 \mathrm{~nm}$ at various corona voltages and ion trap voltages. The particle mass flow rate was fixed at approximately $0.6 \mathrm{~L} / \mathrm{min}$. For the electrostatic loss, the corona and ion trap voltages were varied in the range of approximately $2.8-3.2 \mathrm{kV}$ and $0-300 \mathrm{~V}$, respectively. At the given corona and ion trap voltages, larger particles were found to have lower electrostatic loss. The electrostatic loss increased as the corona and ion trap voltages increased. It is well-known that the electrostatic loss depends on two competing factors: (i) the number of particles that can acquire a charge, which increases with particle size and (ii) the electrical mobility of the particles, which decreases with particle size ${ }^{(28)}$. For particles with a diameter of approximately $20 \mathrm{~nm}$, at an ion trap voltage of $300 \mathrm{~V}$, the highest electrostatic losses were observed to be approximately $73.53 \%, 83.66 \%$, and $53.98 \%$, for corona voltages of $2.8,3.0$, and $3.2 \mathrm{kV}$, respectively. The smaller particles were found to have a higher diffusion loss owing to the Brownian diffusion effect on the particle motion in the discharger than the larger particles. The highest diffusion loss was observed for particles with a diameter of $20 \mathrm{~nm}$, which was approximately $18.9 \%$. 


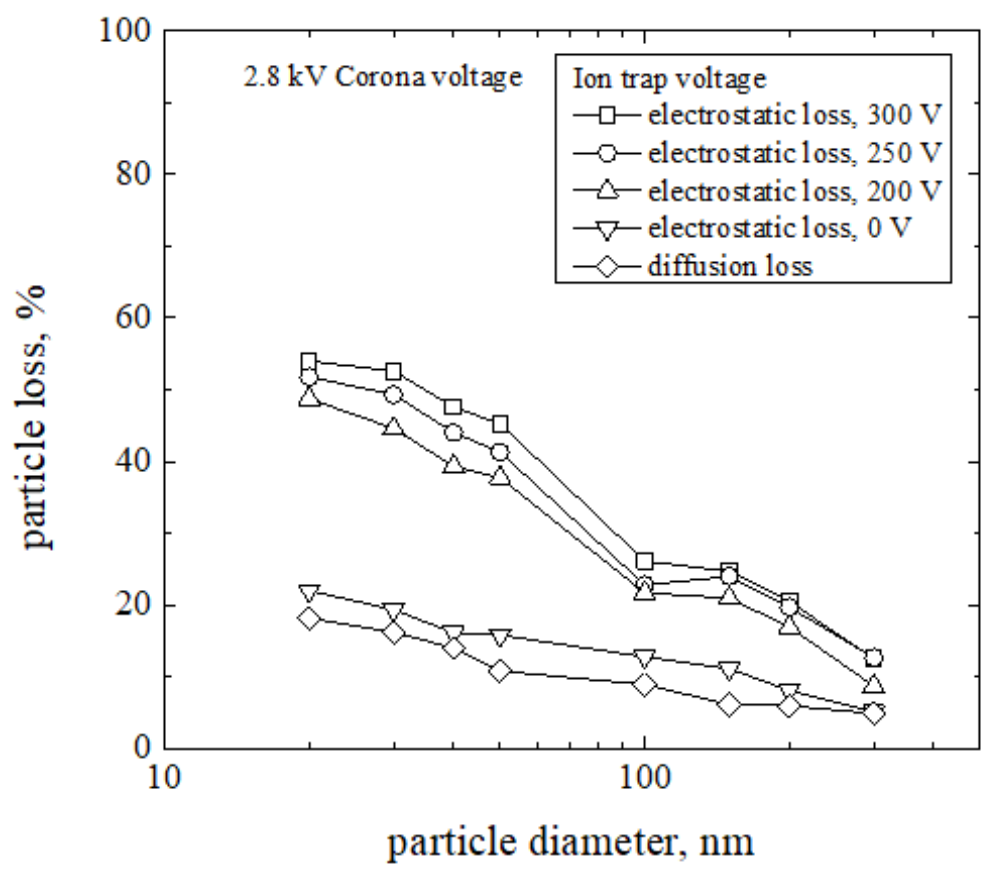

(a) $2.8 \mathrm{kV}$

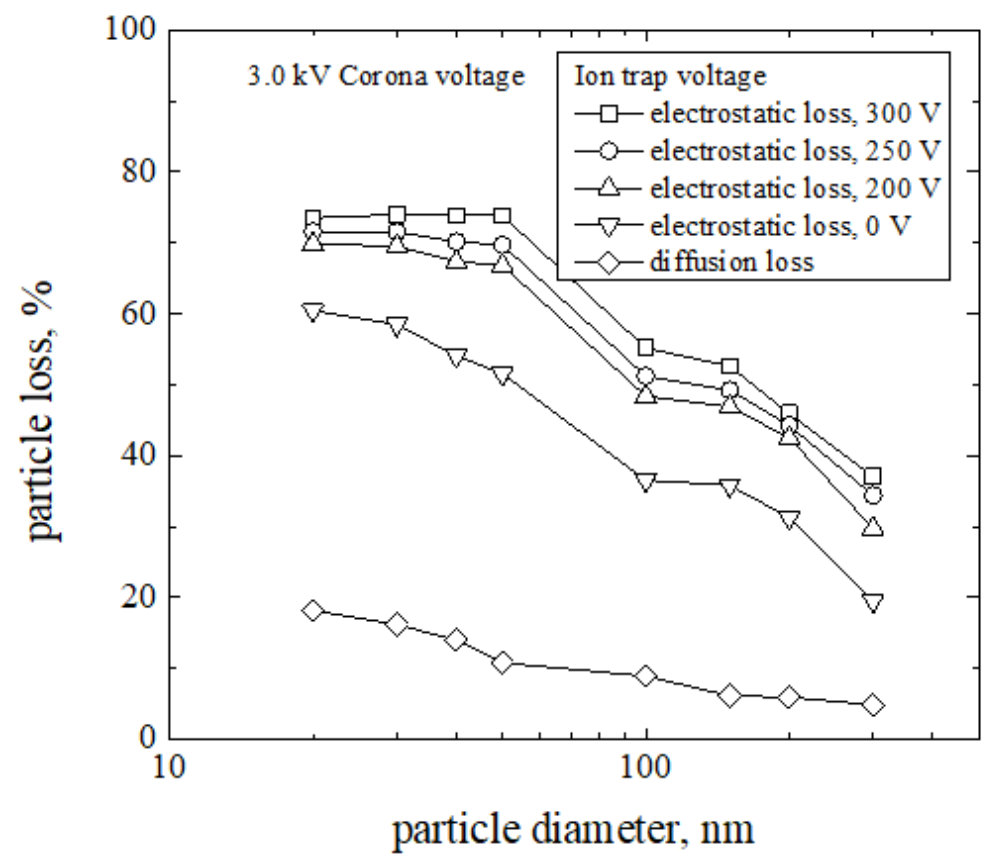

(b) $3.0 \mathrm{kV}$ 


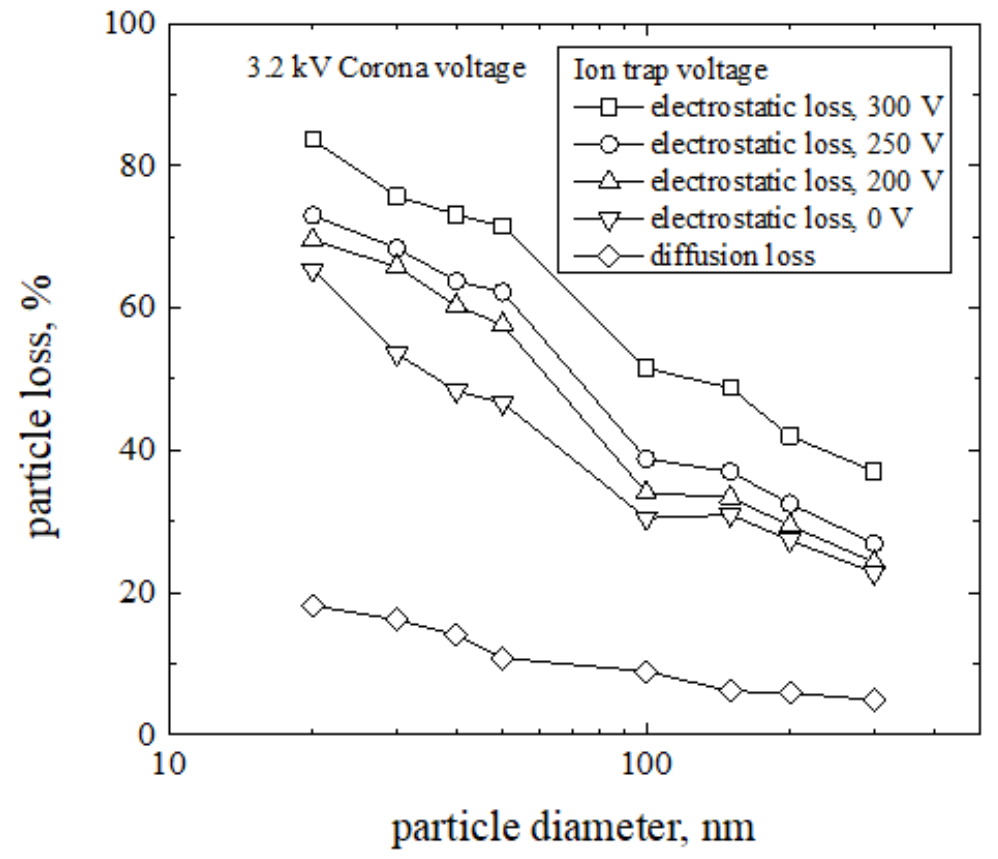

(c) $3.2 \mathrm{kV}$

Fig 8. Particle losses in the discharger as a function of particle diameter

\section{Conclusions}

In this study, a corona discharger for unipolar charging of submicron aerosol particles was developed and experimentally evaluated for intrinsic and extrinsic particle charging efficiencies, and the electrostatic and diffusion particle losses. The charging performance of the discharger was evaluated under different operating conditions, which included corona and ion trap voltages for submicron aerosol particles in the size range of $20-300 \mathrm{~nm}$. The applied voltages of the discharger ranged from 2.4 to 3.2 $\mathrm{kV}$, corresponding to discharge currents of $0.19 \mathrm{nA}$ to $2.0 \mu \mathrm{A}$, and the ion number concentration increased from $1.32 \times 10^{11}$ to $1.03 \times 10^{15}$ ions $/ \mathrm{m}^{3}$. Increasing the corona voltage could lead to a higher discharge current and ion concentration inside the discharger, which in turn, would lead to an increase in the intrinsic charging efficiency. In this discharger, an intrinsic charging efficiency of $74.09-95.08 \%$ was obtained for particles in the size range of $20-300 \mathrm{~nm}$ at the given corona and ion trap voltages. For a given corona voltage, the extrinsic charging efficiency decreased, as the ion trap voltage increased. The best extrinsic charging efficiency of the discharger was found to be approximately $20.80-58.62 \%$ for particle diameters ranging from 20 to $300 \mathrm{~nm}$ at corona and ion trap voltages of approximately $2.8 \mathrm{kV}$ and $200 \mathrm{~V}$, respectively. For particles with a diameter of approximately $20 \mathrm{~nm}$, at an ion trap voltage of $300 \mathrm{~V}$, the highest electrostatic losses were observed to be approximately $73.53 \%$, $83.66 \%$, and $53.98 \%$ for corona voltages of $2.8,3.0$, and $3.2 \mathrm{kV}$, respectively. Finally, a highest diffusion loss of approximately $18.9 \%$ was observed for particles with a diameter of $20 \mathrm{~nm}$.

In addition, the developed discharger has a simple design and robust operation that does not use any additional ion-driving voltage, dilution, or clean flows; furthermore, it is a low-cost system that is easy to construct, and can be used in charging particles for electrical aerosol devices in general applications of airborne particulate monitoring.

\section{Acknowledgements}

The authors gratefully acknowledge the Electricity Generating Authority of Thailand (EGAT), Research contract no. GGR010100089000. The authors wish to thank Prof. Dr. Rainer Zawadzki of Governor State University for the valuable contribution during the preparation of the manuscript. 


\section{References}

1) Fushimi A, Hasegawa S, Takahashi K, Fujitani Y, Tanabe K, Kobayashi S. Atmospheric fate of nuclei-mode particles estimated from the number concentrations and chemical composition of particles measured at roadside and background sites. Atmospheric Environment. 2008;42(5):949-959. Available from: https://dx.doi.org/10.1016/j.atmosenv.2007.10.019.

2) Epa. EPA. National ambient air quality standards for particulate matter. Final Rule, Federal Register, 1997; 62, 38651. 1997. Available from: https: //archive.epa.gov/ttn/pm/web/pdf/pmnaaqs.pdf.

3) Flagan RC. History of Electrical Aerosol Measurements. Aerosol Science and Technology. 1998;28(4):301-380. Available from: https://dx.doi.org/10.1080/ 02786829808965530.

4) Intra P, Tippayawong N. An overview of aerosol particle sensors for size distribution measurement. Maejo International Journal of Science and Technology. 2007;1:120-136. Available from: http://www.mijst.mju.ac.th/vol1/120-136.pdf.

5) Intra P, Tippayawong N. Progress in unipolar corona discharger designs for airborne particle charging: A literature review. Journal of Electrostatics. 2009;67(4):605-615. Available from: https://dx.doi.org/10.1016/j.elstat.2008.12.018.

6) Intra P, Tippayawong N. An Overview of Unipolar Charger Developments for Nanoparticle Charging. Aerosol and Air Quality Research. 2011;11(2):187209. Available from: https://dx.doi.org/10.4209/aaqr.2010.10.0082.

7) Whitby KT. Generator for Producing High Concentrations of Small Ions. Review of Scientific Instruments. 1961;32(12):1351-1355. Available from: https://dx.doi.org/10.1063/1.1717250.

8) Medved A, Dorman F, Kaufman SL, Pöcher A. A new corona-based charger for aerosol particles. Journal of Aerosol Science. 2000;31:616-617. Available from: https://dx.doi.org/10.1016/s0021-8502(00)90625-6.

9) Marquard A, Meyer J, Kasper G. Characterization of unipolar electrical aerosol chargers-Part II: Application of comparison criteria to various types of nanoaerosol charging devices. Journal of Aerosol Science. 2006;37:1069-1080. Available from: https://doi.org/10.1016/j.jaerosci.2005.09.002.

10) Hernandez-Sierra A, Alguacil FJ, Alonso M. Unipolar charging of nanometer aerosol particles in a corona ionizer. Journal of Aerosol Science. 2003;34(6):733-745. Available from: https://dx.doi.org/10.1016/s0021-8502(03)00033-8.

11) Alonso M, Martin MI, Alguacil FJ. The measurement of charging efficiencies and losses of aerosol nanoparticles in a corona charger. Journal of Electrostatics. 2006;64(3-4):203-214. Available from: https://dx.doi.org/10.1016/j.elstat.2005.05.008.

12) Intra P, Tippayawong N. Comparative Study on Electrical Discharge and Operational Characteristics of Needle and Wire-Cylinder Corona Chargers. Journal of Electrical Engineering and Technology. 2006;1(4):520-527. Available from: https://dx.doi.org/10.5370/jeet.2006.1.4.520.

13) Park D, An M, Hwang J. Development and performance test of a unipolar diffusion charger for real-time measurements of submicron aerosol particles having a log-normal size distribution. Journal of Aerosol Science. 2007;38(4):420-430. Available from: https://dx.doi.org/10.1016/j.jaerosci.2007.01.003.

14) Intra P, Tippayawong N. Development and evaluation of a high concentration, high penetration unipolar corona ionizer for electrostatic discharge and aerosol charging. Journal of Electrical Engineering \& Technology. 2013;8(5):1175-1181. Available from: https://doi.org/10.5370/JEET.2013.8.5.1175.

15) Efimov AA, Arsenov PV, Maeder T, Ivanov VV. Unipolar Charging of Aerosol Particles in the Size Range 75-500 nm by Needle-plate Corona Charger. Oriental Journal of Chemistry. 2018;34(1):214-221. Available from: https://dx.doi.org/10.13005/ojc/340124.

16) Intra $P$, Wanusbodeepaisarn $P$, Siri-Achawawath T. Experimental study of charging efficiencies and losses of submicron aerosol particles in a cylindrical tri-axial charger. Iranian Journal of Electrical and Electronic Engineering. 2019;3:401-410. Available from: http://ijeee.iust.ac.ir/article-1-1393-en.pdf.

17) Jidenko N, Bouarouri A, Gensdarmes F, Maro D, Boulaud D, Borra JP. Post-corona unipolar chargers with tuneable aerosol size-charge relations: Parameters affecting ion dispersion and particle trajectories for charger designs. Aerosol Science and Technology. 2021;55(1):12-23. Available from: https://dx.doi.org/10.1080/02786826.2020.1817310.

18) Johnson TJ, Nishida RT, Irwin M, Symonds JPR, Olfert JS, Boies AM. Measuring the bipolar charge distribution of nanoparticles: Review of methodologies and development using the Aerodynamic Aerosol Classifier. Journal of Aerosol Science. 2020;143. Available from: https://dx.doi.org/10.1016/j.jaerosci. 2020.105526.

19) Wei J. Development of a method for measuring surface area concentration of ultrafine particles. Germany. 2007. Available from: https://duepublico2. uni-due.de/receive/duepublico_mods_00016983.

20) Intra P, Yawootti A, Tippayawong N. An electrostatic sensor for the continuous monitoring of particulate air pollution. Korean Journal of Chemical Engineering. 2013;30(12):2205-2212. Available from: https://dx.doi.org/10.1007/s11814-013-0168-7.

21) Murtomaa M, Pekkala P, Kalliohaka T, Paasi J. A device for aerosol charge measurement and sampling. Journal of Electrostatics. 2005;63(6-10):571-575. Available from: https://dx.doi.org/10.1016/j.elstat.2005.03.018.

22) Li L, Chen, Dr, Tsai PJ. Use of an electrical aerosol detector (EAD) for nanoparticle size distribution measurement. Journal of Nanoparticle Research. 2009;11(1):111-120. Available from: https://doi.org/10.1007/s11051-008-9418-8.

23) Rostedt A, Marjamäki M, Yli-Ojanperä J, Keskinen J, Janka K, Niemelä V, et al. Non-Collecting Electrical Sensor for Particle Concentration Measurement. Aerosol and Air Quality Research. 2009;9(4):470-477. Available from: https://dx.doi.org/10.4209/aaqr.2009.03.0023.

24) Lanki T, Tikkanen J, Janka K, Taimisto P, Lehtimäki M. An electrical sensor for long-term monitoring of ultrafine particles in workplaces. Journal of Physics: Conference Series. 2011;304. Available from: https://dx.doi.org/10.1088/1742-6596/304/1/012013.

25) TSI Incorporated. Instruction Manual for Electrical Aerosol Detector Model 3070A. Minnesota, USA. 2002. Available from: https://www.tsi.com/ discontinued-products/electrical-aerosol-detector-3070a/.

26) Intra P, Yawootti A, Rattanadecho P. Corona discharge characteristics and particle losses in a unipolar corona-needle charger obtained through numerical and experimental studies. Journal of Electrical Engineering \& Technology. 2018;12(5):2021-2030. Available from: https://doi.org/10.5370/JEET.2017.12.5. 2021.

27) Chen J, Davidson JH. Ozone production in the negative DC corona. The dependence of discharge polarity Plasma Chemistry and Plasma Processing. 2003;23(3):501-518. Available from: https://doi.org/10.1023/A:1023235032455.

28) English WN. Positive and Negative Point-to-Plane Corona in Air. Physical Review. 1948;74(2):170-178. Available from: https://dx.doi.org/10.1103/ physrev.74.170.

29) Chang J, Kelly AJ, Crowley JM. Handbook of Electrostatic Processes. Dekker M, editor;New York. Marcel Dekker, Inc. $1995 . \quad$ Available from: https://www.taylorfrancis.com/books/e/9781315214559.

30) Bamji SS, Bulinski AT, Prasad KM. Electric field calculations with the boundary element method. IEEE Transactions on Electrical Insulation. 1993;28(3):420-424. Available from: https://dx.doi.org/10.1109/14.236204.

31) Mason J. Breakdown of solid dielectrics in divergent fields. IEE Monograph. 1955;127. Available from: https://doi.org/10.1049/pi-b-1.1955.0143. 
32) Hinds WC. Aerosol Technology. and others, editor;John Wiley \& Sons. 1999. Available from: https://www.wiley-vch.de/en/areas-interest/naturalsciences/aerosol-technology-978-0-471-19410-1.

33) Intra P, Limueadphai P, Tippayawong N. Particulate Emission Reduction from Biomass Burning in Small Combustion Systems with a Multiple Tubular Electrostatic Precipitator. Particulate Science and Technology. 2010;28(6):547-565. Available from: https://dx.doi.org/10.1080/02726351003758444 .

34) Ouf FX, Sillon P. Charging Efficiency of the Electrical Low Pressure Impactor's Corona Charger: Influence of the Fractal Morphology of Nanoparticle Aggregates and Uncertainty Analysis of Experimental Results. Aerosol Science and Technology. 2009;43(7):685-698. Available from: https://dx.doi.org/ $10.1080 / 02786820902878245$.

35) Liu B, Pui D, Kinstley W, Fisher W. Aerosol Charging and Neutralization and Electrostatic Discharge in Clean Rooms. Journal of the IEST. 1987;30(2):4246. Available from: https://dx.doi.org/10.17764/jiet.1.30.2.wx17682658p58871.

36) Romay FJ, Liu BYH, Pui DYH. A Sonic Jet Corona Ionizer for Electrostatic Discharge and Aerosol Neutralization. Aerosol Science and Technology. 1994;20(1):31-41. Available from: https://dx.doi.org/10.1080/02786829408959661.

37) Sakata S, Okada T. Effect of humidity on hydrated cluster-ion formation in a clean room corona discharge neutralizer. Journal of Aerosol Science. 1994;25(5):879-893. Available from: https://dx.doi.org/10.1016/0021-8502(94)90054-x.

38) Sato K, Takahashi H, Sakata S, Okada T. Effect of organicsolvent-gas on chemical formation of air ions produced by corona discharge. In: Proceedings of the 12th ISCC. 1994;p. 7-14.

39) Ichitsubo H, Alonso M, Ishii M, Endo Y, Kousaka Y, Sato K. Behavior of Ultrafine Particles generated from organic vapors by corona ionizers. Particle and Particle Systems Characterization. 1996;13:41-46. Available from: https://dx.doi.org/10.1002/ppsc.19960130108. 